\title{
IMPACT OF ACCESSION TO EMU ON INTERNATIONAL TRADE - CASE OF THE CZECH REPUBLIC
}

\author{
Filip Tichý*
}

\begin{abstract}
:
The goal of this paper is to determine one of the consequences of accession of the Czech Republic to the European Monetary Union. The gravity equation is used to estimate the impact of exchange rate volatility and currency unions on international trade. Model's variables include GDPs per capita and populations of each partners, distance between them, exchange rate volatility and several dummy variables, including those, that are signifying membership of given country in the euro area. This model is estimated by general least squares method using panel data for members of the European Union.
\end{abstract}

Keywords: exchange rate volatility, international trade, gravity model, panel data, monetary union

JEL Classification: C51, F13, F15

\section{Introduction}

In recent years we have been witnessing the intensive convergence process of the new member states of the European Union to the "older" member states. The Czech Republic is not an exception. This convergence process is noticeable on almost all levels of its economy. The monetary policy is just one of them. Nevertheless, it is one of the most discussed topics because the new EU member states must decide or have already decided theirs dates of accession to the European Monetary Union. The goal of this paper is to determine one of the consequences of accession of the Czech Republic to the European Monetary Union.

The accession to the euro area is connected with fulfillment of the Maastricht's criteria. These are well-known and it will be pointless to introduce them here. But the EMU membership's consequences are far more complex than just meeting these requirements. The question that this paper is focused on is the impact of accession of the Czech Republic to the EMU on international trade of the Czech Republic. To answer this, at least partially, we must first realize what will change because of fixed exchange rate when we accept the euro as a legal tender.

* University of Economics, Prague (TichyF@vse.cz).

Paper is supported by Grant Agency of the Czech Republic, project No. 402/06/0190. 
The first obvious effect is that there will be neither appreciation nor depreciation of the exchange rate between the member states. Yet this effect's result is difficult to assess. There is a question whether the potential changes in the exchange rate will be transferred to the domestic inflation or not. There are several theories and many papers concerning this topic and it will not be further analysed in this study.

The second effect is that there will be no exchange rate volatility between the Czech Republic and the member states of euro area. Also, in relation to other currencies, the Czech Republic will acquire the volatility of euro exchange rate. To illustrate this, you can see the current volatility of exchange rate CZK/EUR on the graph bellow (see Figure 1).

Figure 1

Daily Nominal Exchange Rate CZK/EUR - year 2006

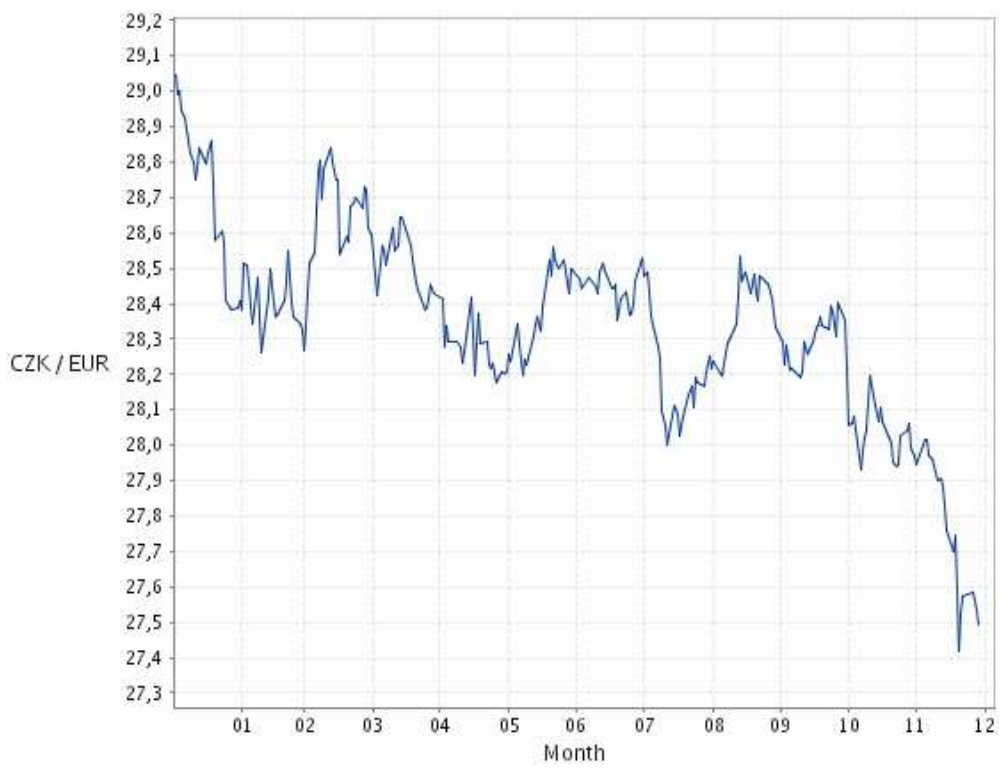

Source: Czech National Bank

There are several papers focusing on the exchange rate volatility and its impact on the international trade. Summary of those papers can be found in study from Baldwin et al. (2005). The conclusions are quite heterogeneous. In studies using panel data for estimation, there is mostly significant relation between international trade and exchange rate volatility, but that does not always hold for studies using time series or cross-section data.

The paper from A. K. Rose (2000) turned out to be very significant. He came with the idea that when exchange rate volatility is reduced to zero permanently then the increase in trade is higher than the increase predicted by model. In other words, after forming of a monetary union by two countries there is a discrete jump in volume of mutual trade. This effect became known as the "Rose" effect. But if this effect is real or just a result of wrong model remains unsolved. There are quite a few papers that try to verify or refute this assertion, but again the results are very heterogeneous. 
In this paper, we will try to determine the impact of accession of the Czech Republic to the European Monetary Union on its international trade. To achieve this, the modified gravity equation of trade will be estimated using panel data. In order to bring the estimation closer to the Czech Republic, we will narrow the panel data only for current member states of the European Union. We will try as well to control the model for the "Rose" effect through dummy variables.

\section{Gravity Equation}

\subsection{Original and Modified Gravity Equation}

The original gravity equation dates to 1687 , when Isaac Newton introduced it as "General law of gravity". The specification of the gravity equation is:

$$
F_{i j}=g \frac{m_{i} m_{j}}{d_{i j}^{2}},
$$

where $F_{i j}$ is the value of gravity force, $m_{i(j)}$ is the weight of object $i(j), d_{i j}$ is the distance between the objects and $g$ is gravity constant.

With only a slight modification, this model is successfully used in many other disciplines than physics. They are mostly interested in something we can call "social relationships", such as volume of migration, international travel, transportation and so on. The modified form of gravity equation can be expressed as:

$$
F_{i j}=G \frac{M_{i}^{\alpha} M_{j}^{\beta}}{D_{i j}^{\theta}},
$$

where $\alpha, \beta$ and $\theta$ are the parameters of the modified equation, $F_{i j}$ is the volume of endogenous variable, $M_{i(j)}$ is the volume of relevant exogenous variable for country $i(j), D_{i j}$ is the distance between these two countries and $G$ is model's constant.

\subsection{Gravity Equation of Trade}

One of the domains, where the gravity equation is applied, is international trade. This approach was introduced by Jan Tinbergen (1962). In spite of the fact that many economists object that this model has no theoretic foundation, the gravity equation is frequently used in international trade. Moreover, this objection is not a fair one. Today, there are several papers concerning the theory behind this model.

Because this study is focused on the estimation of the gravity equation, we will only highlight the basic idea of this theory. The complete derivation can be found in paper from J. H. Bergstrand (1985).

Let's assume $N$ countries with international trade. Consumers in each country $j$ have the same constant elasticity of substitution (CES) utility function 


$$
\left.U_{j}=\left\{\left[\sum_{k=1}^{N} X_{k j}^{\frac{\sigma_{j}-1}{\sigma_{j}}}\right)^{\frac{\sigma_{j}}{\sigma_{j}-1}}\right]^{\frac{\mu_{j}-1}{\mu_{j}}}+X_{j j}^{\frac{\mu_{j}-1}{\mu_{j}}}\right\}^{\frac{\mu_{j}}{\mu_{j}-1}} \quad, j=1,2, \ldots, N,
$$

where $X_{k j}$ is amount of $k$ 's aggregate goods demanded by $j$ 's consumers, $\mu_{j}$ is the CES between domestic and importable goods in $j\left(0 \leq \mu_{j} \leq \infty\right)$ and $\sigma_{j}$ is the CES between importables in $j\left(0 \leq \sigma_{j} \leq \infty\right)$. In maximizing theirs utility, the consumers are constrained by income

$$
Y_{j}=\sum_{k=1}^{N}\left(\frac{P_{k j} T_{k j} C_{k j}}{E_{k j}} X_{k j}\right), j=1,2, \ldots, N,
$$

where $P_{k j}$ is the $k$-currency price of $k$ 's product sold in $j$ 's market, $T_{k j}$ is $j$ 's tariff rate on $k$ 's product plus one, $C_{k j}$ is the transport cost between $k$ and $j$ and $E_{k j}$ is the spot exchange rate. Maximizing (2.3) subject to (2.4) leads to $N(N-1)$ bilateral aggregate import demand equations and $N$ domestic demand equations

In each country $i$, firms maximize the profit function

$$
\Pi_{j}=\sum_{k=1}^{N}\left(P_{i j} X_{i j}\right)-W_{i} R_{i}, \quad i=1,2, \ldots, N,
$$

where $R_{i}$ is the amount of the internationally immobile resource in $i$ and $W_{i}$ is the $i$-currency value of a unit of $R_{i}$. In each country is the resource allocated according to the constant elasticity of transformation (CET) joint production surface

$$
R_{i}=\left\{\left[\left(\sum_{\substack{k=1 \\ k \neq i}}^{N} X_{i k}^{\frac{\gamma_{i}+1}{\gamma_{i}}}\right)^{\frac{\gamma_{i}}{\gamma_{i}+1}}\right]^{\frac{\eta_{i}+1}{\eta_{i}}}+X_{i i}^{\frac{\eta_{i}+1}{\eta_{i}}}\right\}^{\frac{\eta_{i}}{\eta_{i}+1}}, \quad i=1,2, \ldots, N,
$$

where $\eta_{i}$ is i's CET between production for home and foreign markets $\left(0 \leq \eta_{i} \leq \infty\right)$ and $\gamma_{i}$ is the CET for production among export markets $\left(0 \leq \gamma_{i} \leq \infty\right)$. Maximizing (2.5) subject to (2.6) leads to $N(N-1)$ bilateral aggregate export supply equations and $N$ domestic supply equations. The equilibrium conditions are

$$
X_{i j}=X_{i j}^{D}=X_{i j}^{S}, \quad i, j=1,2, \ldots, N,
$$

where $X_{i j}$ is the actual volume of trade from $i$ to $j$. 
To solve these equations we need first two assumptions. The first assumption is that the market for the aggregate trade flow from $i$ to $j$ is small relative the other markets. The second assumption is that utility and production functions are identical across countries. The solution of this system leads to "general" gravity equation. The exact equation and its derivation can be found in paper from J. H. Bergstrand (1985). Another theoretical study focused on gravity equation has been for example done by J. E. Anderson (1997).

In this paper there will be used simplified version of "general" gravity equation. We will exclude several price indices. This is in line with other studies of gravity equation. The simplified econometric gravity equation of trade can be thus written as:

$$
X_{i j}=\alpha Y_{i}^{\beta_{1}} Y_{j}^{\beta_{2}} \operatorname{Pop}_{i}^{\beta_{3}} \operatorname{Pop}_{j}^{\beta_{4}} E R_{i j}^{\beta_{5}} D_{i j}^{\beta_{6}} \prod_{l} \operatorname{Dum}_{l}^{\gamma_{1}} u_{i j},
$$

where $X_{i j}$ is the volume of trade (import, export) from country $i$ to $j, Y_{i(j)}$ is GDP per capita of country $i(j), P o p_{i(j)}$ is population of relevant country, $E R_{i j}$ is the spot exchange rate, $D_{i j}$ is distance, Dum $_{l}$ are the dummies of the model (common border, membership in currency union, time dummies), $\alpha, \beta_{k}$ and $\gamma_{l}$ are the unknown parameters of the model.

\subsection{Gravity Equation and Exchange Rate Volatility}

In order to add the exchange rate volatility into the equation (2.8), we must analyse the form of dependency between trade and exchange rate volatility. The gravity equation is nonlinear, therefore the relationship between trade and exchange rate volatility must be also nonlinear. This has been analysed by Baldwin et al. (2005) which yielded the conclusion that this relationship is indeed convex instead of linear.

The exact deduction of this is in theirs paper, but we will try to highlight the basic idea. In European economies, there are mainly small companies and most of them do not participate in international trade. One of the reasons is that this type of trade is connected with large uncertainty. Among factors that influence this uncertainty is the exchange rate volatility. Decrease in the volatility thus evokes two effects: (a), the firms that are already participating in international trade will increase the volume of this trade; (b) some new companies will enter the international market, this mainly affects small companies, because the exchange rate uncertainty is likely only nuisance for the bigger ones. And because of this second effect, the reaction of trade on decrease in exchange rate volatility is not linear.

Slight modification in (2.8) results in gravity equation of trade with exchange rate volatility. Thus we can write:

$$
X_{i j}=\alpha Y_{i}^{\beta_{1}} Y_{j}^{\beta_{2}} \operatorname{Pop}_{i}^{\beta_{3}} \operatorname{Pop}_{j}^{\beta_{4}} E R_{i j}^{\beta_{5}} D_{i j}^{\beta_{6}} e^{\beta_{7}\left(E R_{i j}\right)} \prod_{l} \operatorname{Dum}_{l}^{\gamma_{1}} u_{i j},
$$

where $V\left(E R_{i j}\right)$ is the volatility of bilateral exchange rate between countries $i$ and $j$. To avoid error due to rounding during data transformation, the exchange rate volatility has been used in exponent in (2.9). 


\section{Estimation of Gravity Equation of Trade}

For empirical testing, we transformed equation (2.9) to a log-linear form:

$$
\begin{aligned}
x_{i j}=\ln (\alpha)+\beta_{1} y_{i}+\beta_{2} y_{j} & +\beta_{3} \text { pop }_{i}+\beta_{4} \text { pop }_{j}+\beta_{5} e r_{i j}+\beta_{6} d_{i j}+\beta_{7} V\left(E R_{i j}\right) \\
& +\sum_{l} \gamma_{l} d u m_{l}+\ln \left(u_{i j}\right)
\end{aligned}
$$

where small characters express logarithm of the original value.

\subsection{Data}

We have used panel data to estimate (3.1). We have the annual data at our disposal and the time period span from 1997 to 2005. The time series has been collected for member countries of EU25 (excluding Cyprus) plus Norway and Switzerland.

In the following table (see Table 1) you can find the sources of our retrieved data.

Table

Data Description and Sources

\begin{tabular}{|l|l|l|}
\hline \multicolumn{1}{|c|}{ Variable } & \multicolumn{1}{|c|}{ Description } & \multicolumn{1}{c|}{ Source } \\
\hline$X_{i j}$ & Export from country $i$ to country $j$; in US\$ & IMF - DOTS \\
\hline$Y_{i(j)}$ & $\begin{array}{l}\text { GDP per capita for country } i(j) \text { in constant } \\
\text { price; in US\$ }\end{array}$ & IMF - WEO \\
\hline$P o p_{i(j)}$ & Population of country $i(j)$ & UN \\
\hline$D_{i j}$ & Distance between countries $i$ and $j$ & www.cepii.fr \\
\hline$E R_{i j}$ & $\begin{array}{l}\text { Spot exchange rate between countries } i \\
\text { and } j\end{array}$ & Bloomberg and Czech National Bank \\
\hline$V\left(E R_{i j}\right)$ & $\begin{array}{l}\text { Volatility of bilateral exchange rate } \\
\text { between countries } i \text { and } j\end{array}$ & $\begin{array}{l}\text { Authors calculations using data from } \\
\text { Bloomberg and Czech National Bank }\end{array}$ \\
\hline
\end{tabular}

The dummies used in the estimation are listed in the following table (see Table 2).

Table 2

Dummy Variable Description and Sources

\begin{tabular}{|l|l|l|}
\hline \multicolumn{1}{|c|}{ Dummy variable } & \multicolumn{1}{c|}{ Description } & \multicolumn{1}{c|}{ Source } \\
\hline Bord $_{i j}$ & Common border between countries $i$ and $j$ & Author's calculations \\
\hline$E M U 1_{i j}$ & One of countries $i$ an $j$ is member of euro area & Author's calculations \\
\hline$E M U 2_{i j}$ & Both of countries $i$ an $j$ are members of euro area & Author's calculations \\
\hline$T\left(\right.$ Year $\left._{t}\right)$ & $\begin{array}{l}\text { For each year (excluding the first one), there is time } \\
\text { dummy to adjust the model for trend. }\end{array}$ & Author's calculations \\
\hline
\end{tabular}

The model's endogenous variable is the volume of bilateral export between two countries, thus for 26 countries that makes 650 combinations of different partners. Finally for all of these combinations we have collected 9 years time series. In total that makes 5,850 observations that can be used to model estimation. 


\subsection{Measure of Exchange Rate Volatility}

As measure of exchange rate volatility, we have used variance of returns of exchange rate from daily data, according to the following formula:

$$
V\left(E R_{i j}\right)=\frac{1}{n} \sum_{d=1}^{n}\left(\frac{S_{i j, d}}{S_{i j, d-1}}-\frac{1}{n} \sum_{l=1}^{n} \frac{S_{i j, l}}{S_{i j, l-1}}\right)^{2},
$$

where $S_{i j}$ is the spot exchange rate and $n$ is number of days in year $t$.

\subsection{Method of Estimation}

When using ordinary least squares (OLS) based methods on panel data, we must first decide whether the data set has fixed or random effects.

The fixed effects are when the heterogeneity in the model is unobservable but correlated with any variable included in the model. This heterogeneity can be controlled through added dummy variables. These dummy variables are associated with each unit less one in the cross-section dimension of the panel dataset. OLS are then applied to this extended model. This is known as least squares dummy variable (LSDV). In our case we would have to add 649 of these dummy variables.

The heterogeneity in random effects is again unobservable but this we presume that it is uncorrelated with any model's variable. General least square (GLS) can be used to estimate model with random effects. In the first step we acquire the residuals by standard OLS applied to the model. Then we compute transformation matrix that is used in GLS estimator.

The Breusch-Pagan Lagrange multiplier test can be used to decide whether data set shows fixed or random effects. The null hypothesis speaks for fixed effects and the alternate hypothesis speaks for random effects. The test criteria is calculated from

$$
L M=\frac{n T}{2(T-1)}\left[\frac{\sum_{i=1}^{n}\left(\sum_{t=1}^{T} e_{i t}\right)^{2}}{\sum_{i=1}^{n} \sum_{t=1}^{T} e_{i t}^{2}}-1\right]^{2},
$$

where $T$ is the length of time series, $n$ is the number of unit in cross-section dimension and $e_{i t}$ is residuum acquired by OLS. The $L M$ has approximately $\chi^{2}$ with one degree of freedom.

\subsection{Results of Regression}

The final estimator has been chosen according to Breusch-Pagan $L M$ test. Thus, the equation (3.1) has been estimated by the GLS for panel data using residuals obtained from estimation by OLS. The software product GiveWin with PcGive modul has been 
used to perform the estimation. The results of this estimation are displayed in the following table (see Table 3). There are only included statistically significant variables in this table because the insignificant ones have been excluded before the final estimation.

Table 3

Regression Results

\begin{tabular}{|c|c|c|}
\hline Variable & Coefficient estimation & Standard error \\
\hline Constant & -17.75250 & 0.69790 \\
\hline$y_{i}$ & 1.03036 & 0.03248 \\
\hline$y_{j}$ & 0.73648 & 0.03250 \\
\hline$p_{i} p_{i}$ & 0.89540 & 0.02188 \\
\hline$p p_{j}$ & 0.88101 & 0.02196 \\
\hline$d_{i j}$ & -1.37115 & 0.06327 \\
\hline$V\left(E R_{i j}\right)$ & -2161.26 & 300.2 \\
\hline$B o r d_{i j}$ & 0.32840 & 0.12000 \\
\hline$T 1998$ & 0.111460 & 0.01826 \\
\hline$T 1999$ & 0.131090 & 0.02327 \\
\hline$T 2000$ & 0.387150 & 0.02402 \\
\hline$T 2001$ & 0.476119 & 0.02408 \\
\hline$T 2002$ & 0.409122 & 0.02381 \\
\hline$T 2003$ & 0.312949 & 0.02473 \\
\hline$T 2004$ & 0.152239 & 0.02781 \\
\hline$T 2005$ & 0.199987 & 0.02915 \\
\hline
\end{tabular}

Except for parameters by dummy variables $E M U 1$ and $E M U 2$ and variable for $E R_{i j}$, all estimated parameters are statistically significant even on $1 \%$ level of significance. All significant parameters have expected orientation and their values are with line of other papers.

The question is why the parameters by dummies EMU1 and EMU2 are statistically insignificant. The answer may lie in the time dummies. You can see that there is a quite significant increase in the parameter's values of the time dummies between years 1999 and 2000. And because this is the period, when most of the EMU1 and EMU2 are changing values, it might have been possible, that the estimation function could not distinguish the "Rose" effect from trend. There is a drawback to this hypothesis and that's because the parameter's value of time dummies has lowered for years 2004 and 2005. So it is possible that this effect did not occur and the increase or the latter decrease has been caused by other factor, such as price shocks, shift in export structure to the countries not included in this study because of change in EURO exchange rate, overoptimistic expectations after joining the EMU and so on. To answer which one of these hypotheses is correct, more extensive research is required.

\section{Effect of Exchange Rate Volatility on the Czech International Trade}

On the first glance the value of the estimated parameter for $V\left(E R_{i j}\right)$ appears to be quite high, but we must bear in mind that the exchange rate volatility is computed from daily 
data and because of that, its value is extremely low. In the following table (see Table 4) we will demonstrate the impact of exchange rate volatility on the Czech international trade. The values in the table represent percentage level on which the international trade of the Czech Republic decreased because of exchange rate volatility. If there was no volatility, that value would be 100 .

Table 4

Impact of Exchange Rate Volatility on the Czech International Trade

\begin{tabular}{|l|c|c|c|c|c|c|}
\hline & $\mathbf{2 0 0 0}$ & $\mathbf{2 0 0 1}$ & $\mathbf{2 0 0 2}$ & $\mathbf{2 0 0 3}$ & $\mathbf{2 0 0 4}$ & $\mathbf{2 0 0 5}$ \\
\hline EMU & 96.83 & 97.30 & 97.95 & 97.47 & 96.90 & 97.89 \\
\hline Denmark & 97.81 & 97.20 & 96.59 & 97.48 & 98.19 & 98.46 \\
\hline Estonia & 96.73 & 95.00 & 92.23 & 97.49 & 97.99 & 98.26 \\
\hline Hungary & 96.83 & 94.89 & 94.83 & 90.14 & 95.83 & 98.35 \\
\hline Iceland & 94.97 & 88.00 & 92.29 & 93.96 & 95.21 & 93.82 \\
\hline Latvia & 92.02 & 93.04 & 90.14 & 96.74 & 95.95 & 97.59 \\
\hline Lithuania & 92.04 & 91.39 & 91.88 & 95.18 & 94.66 & 97.73 \\
\hline Norway & 96.94 & 95.83 & 95.60 & 94.36 & 95.84 & 97.30 \\
\hline Poland & 89.97 & 90.34 & 90.77 & 92.63 & 93.91 & 96.19 \\
\hline Slovak Republic & 95.99 & 95.05 & 95.39 & 97.72 & 98.06 & 98.66 \\
\hline Slovenia & 94.08 & 94.15 & 87.60 & 94.86 & 98.17 & 98.45 \\
\hline Sweden & 95.87 & 94.87 & 94.35 & 96.62 & 97.32 & 97.69 \\
\hline Switzerland & 96.83 & 96.03 & 95.72 & 96.65 & 97.54 & 98.02 \\
\hline United Kingdom & 89.74 & 95.81 & 86.27 & 99.39 & 95.90 & 94.46 \\
\hline
\end{tabular}

One of the important questions for the Czech Republic is whether and when to join the euro area. Now we will try to express the effect of adoption euro as currency on the Czech international trade. Because any prediction of exchange rate volatility is questionable at least, we will use the known values of exchange rate volatility for year 2006. In the following table (see Table 5) you can see on what percentage level the international trade of the Czech Republic was lowered in 2006 because of exchange rate volatility and next to it there is the hypothetical value for the case if the Czech Republic had already euro as national currency.

As can be seen, the adoption of ruro as national currency will have mostly positive effect on international trade of the Czech Republic. The only real suggestion to the policy makers resulting from this model is that the Czech Republic should coordinate its date of accession to the euro area with countries as Hungary, Poland and the Slovak Republic. If the Czech Republic joins European Monetary Union ahead of these countries or later then they, it might results in the decrease of the international trade between them as a result of higher exchange rate volatility. 
Table 5

Effect of Joining Euro Area on the Czech International Trade

\begin{tabular}{|l|c|c|c|}
\hline \multirow{2}{*}{} & & \multicolumn{2}{|c|}{ Czech Republic } \\
\cline { 2 - 4 } & Currency & CZK & EUR \\
\hline EMU & EUR & 98.51 & 100.00 \\
\hline Estonia & DKK & 98.90 & 98.65 \\
\hline Hungary & EEK & 98.88 & 98.66 \\
\hline Iceland & HUF & 96.21 & 94.21 \\
\hline Latvia & ISK & 87.79 & 91.22 \\
\hline Lithuania & LTL & 98.43 & 98.71 \\
\hline Norway & LVL & 98.32 & 98.69 \\
\hline Poland & NOK & 96.92 & 98.38 \\
\hline Slovak Republic & PLN & 97.13 & 94.85 \\
\hline Slovenia & SKK & 98.70 & 95.84 \\
\hline Sweden & SIT & 98.79 & 98.67 \\
\hline Switzerland & SEK & 97.98 & 98.31 \\
\hline United Kingdom & CHF & 98.09 & 98.50 \\
\hline
\end{tabular}

\section{Conclusion}

The motivation for this study was to bring some new evidence to the problem of accession of the Czech Republic to the euro area. We have chosen less known topic that is nevertheless important if we want to know the complete set of advantages and disadvantages that stem from euro adoption.

In this study we did not take into account the period during which the Czech Republic will reside in ERM II system. The reason for this is very simple. The Czech Republic would meet the requirements of ERM II system with current development of its exchange rate $\mathrm{CZK} / \mathrm{EUR}$. Thus there is no reason to assume any significant change in the exchange rate volatility of Czech koruna under the ERM II system.

The estimation based on gravity equation suggests a statistically significant relationship between exchange rate volatility and international trade. For the Czech Republic we have demonstrated the intensity of this relation (see Table 4). Next, we have tried to figure out the effect of adopting euro as national currency (see Table 5). We were not successful in determining the real value of the dummies expressing the membership in currency union (the "Rose" effect); to do so, additional research is required.

This paper does not try to give an answer to when and if the Czech Republic should join the euro area. In order to do so, more extensive study and more complex model are needed. We only try to assess one small part of this complicated problem. As a result of this study we can say that with adoption of euro the international trade of the Czech Republic will very likely increase.

To acquire full potential of this increase, the accession should be coordinated with other nations, such as Hungary, Poland and the Slovak Republic. If these countries adopt euro and the Czech Republic will retain Czech koruna then it will most likely 
harm its trade with them. In the following table (see Table 6) you can see the impact of different values of exchange rate volatility on export of the Czech Republic to the above mentioned countries. Several scenarios are considered.

Table 6

Czech Export to Neighbouring Countries - Several Scenarios

\begin{tabular}{|l|c|c|c|}
\hline \multirow{2}{*}{ Hungary } & & \multicolumn{2}{|c|}{ Czech Republic } \\
\cline { 2 - 4 } & Currency & EUR & CZK \\
\hline \multirow{2}{*}{ Poland } & EUR & 100.00 & 98.51 \\
\cline { 2 - 4 } & HUF & 94.21 & 96.21 \\
\hline \multirow{2}{*}{ Slovak Republic } & EUR & 100.00 & 98.51 \\
\cline { 2 - 4 } & PLN & 94.85 & 97.13 \\
\cline { 2 - 4 } & EUR & 100.00 & 98.51 \\
\hline
\end{tabular}

\section{Reference}

Anderson, J.E. (1997), "A Theoretical Foundation for Gravity Equation." American Economic Review, 69, pp. 106-116.

Baldwin, R., Skudelny, F., Taglioni, D. (2005), "Trade Effects of the Euro, Evidence from Sectoral Data." European Central Bank Working Paper Series No. 446.

Bergdstrand, J.H. (1985), "The Gravity Equation in International Trade: Some Microeconomic Foundations and Empirical Evidence." The Review of Economics and Statistics, 67 (3), pp. 474-481.

Gujarati, D.N. (2003), Basic Econometrics. Singapore : McGraw-Hill Higher Education.

Rose, A.K. (2000), "One Money, One Market: Estimating the Effect of Common Currencies on Trade." Economic Policy, 30, pp. 7-76.

Tinbergen, J. (1962), Shaping the World Economy: Suggestions for an International Economic Policy. New York : Twentieth Century Fund. 